\title{
Urgences
}

\section{Gilbert Dupuis, La tête dans le crin, Saint-Gabriel de Rimouski,} Les Éditions Passages, 1981.

\section{Lise Lessard}

Numéro 4, 2e trimestre 1982

URI : https://id.erudit.org/iderudit/025066ar

DOI : https://doi.org/10.7202/025066ar

Aller au sommaire du numéro

Éditeur(s)

Urgences

ISSN

0226-9554 (imprimé)

1927-3924 (numérique)

Découvrir la revue

Citer ce compte rendu

Lessard, L. (1982). Compte rendu de [Gilbert Dupuis, La tête dans le crin, Saint-Gabriel de Rimouski, Les Éditions Passages, 1981.] Urgences, (4), 87-89.

https://doi.org/10.7202/025066ar d'utilisation que vous pouvez consulter en ligne.

https://apropos.erudit.org/fr/usagers/politique-dutilisation/ 


\section{PARUTIONS COMMENTÉES}

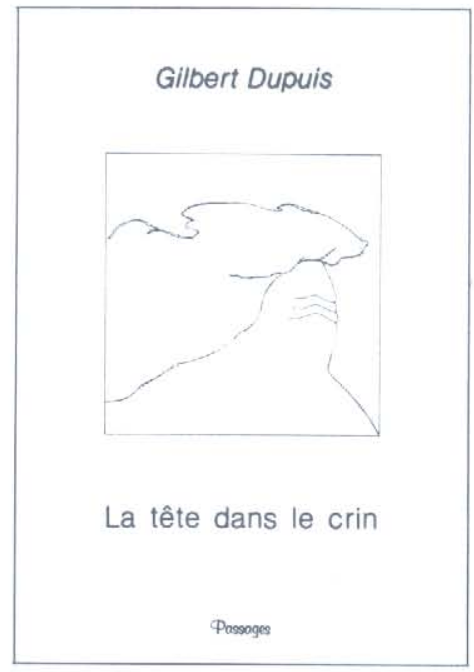

LA TÊTE DANS LE CRIN, Gilbert Dupuis, Les Éditions Passages, 1981.

Dans les "temps et lieux" de la littérature d'ici, LA TÊTE DANS LE CRIN est une oeuvre importante. Gilbert Dupuis président du Salon du Livre de Rimouski et I'un des fondateurs de notre Regroupement régional d'écrivains - pose une fois de plus un geste exemplaire: il publie à compte d'auteur, parmi des textes écrits au cours des dernières années, ceux qui témoignent le mieux de son "parcourir" de poète. C'est presque l'album photographique d'un "écrire pour voir et voir pour écrire". Car, cinq fois, le regard s'est immobilisé...

...sur la convoitise de l'enfance pour le monde adulte s'offrant le rire après la sueur. Des mots de Fête et d'épopées anciennes, quand gigue et chicane se frôlaient du jupon les samedis de salle paroissiale, et que les gars "brylcreemés" courtisaient dans leurs chars les filles rencontrées au soleil des galeries, les beaux dimanches après-midi... 
...sur "I'âme molle" adolescente prenant le risque des tendresses, où la bouche est centrale, où la langue et la lèvre ourdissent des complots, où s'avance goulûment la peau des paumes... Et le langage devient fougueux quand le "jouir" se fait imminent: "il y a des fêtes pleines d'appétits boulimiques/et des jeux à mener sous la soie et le denim" (p. 60) "voici que dans ma tête la liberté se débauche / j'encule le squelette de la mort en me tordant de rire / et fourre mon doigt dans l'oeil qui regardait Caïn" (p. 67).

...sur les masques qu'on jette en des mots lents et simples... La pause est belle à son troisième regard, avec l'omniprésence de la musique pour charmer le dehors; avec l'outil majeur que devient l'être tout entier dans l'acte de se reconnaître le dedans: "il y a des torrents dans ma hâte / des tourbillons dans ma tête de blé / dans ma bouche d'urgence il y a des anges pompiers" (p. 81). L'évidence de se vouloir en équilibre claque comme une gifle: "se conduire en homme mûr: c'est-à-dire prêt à tomber.." (p. 97) et fouille dans les machinations du futur sans trouver rien qui vaille. Pour qu'enfin, et avec insistance, le corps le coeur et l'âme en appellent à I'unique voix nombreuse... "Il nous faut lâcher nos grands fauves à mouchetures de sucre / dans les espaces sauvages de notre noirceur / il nous faut sortir le rire des fièvres et débrider la fête des mortels solidaires" (p. 101).

À la photo quatrième, l'humour s'installe pour un brin d'intermède. Junot Bralune, un coin de coeur bafoué par sa belle, raconte ses trois suicides... A lire, pour en tout cas connaître une façon certaine de rire du mourir d'amour...

À l'espace cinquième de I'oeil, celui “De l'euphorie dans son vin", le mot magique, aux syllabes amorcées par le coeur grand ouvert sur l'unique voix nombreuse, se transmet de belle et grande manière. "D'espoir et de poésie" est un manifeste en soi. (Un grand et beau texte!) Avec l'appétence saccadée des toutes premières pages, avec une conviction catégorique dans les "je

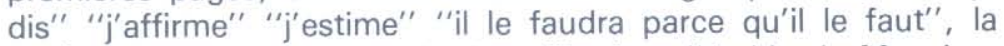
POÉSIE brille comme le brin de paille dans l'étable de Monsieur Rimbaud. C'est elle qui permet l'espoir aux grands patenteux du "dire"!... (Ce que fait Gilbert Dupuis quand il "grand galope", 
"s'enfant-prodigue", "se pilote automatique", se mêle de "comprenure", d"'achalerie", de quand "le monde 'bière"' et que "ça snorraude" !)

Me plaisent ces rouges perspectives du Langage. Dans I'absolu... lisiblement!

Lise Lessard

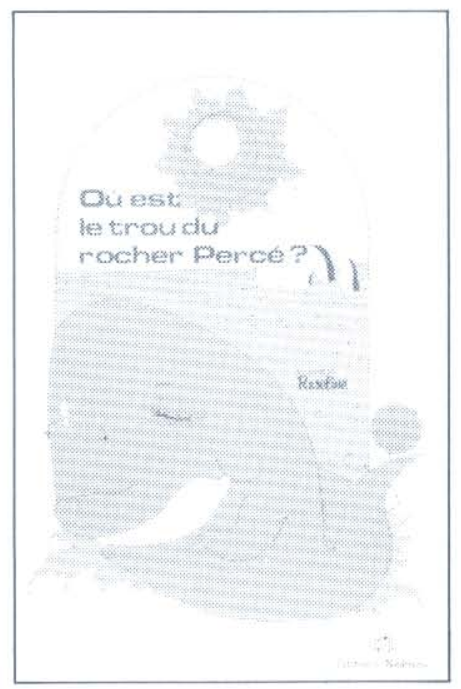

OỦ EST LE TROU DU ROCHER PERCÉ?, Roselyne GrandMaison et Michel Cayouette, Naaman, 1981.

Ėcrire pour les enfants n'est pas une entreprise aisée. II suffit à quiconque de $s^{\prime} y$ aventurer pour s'en convaincre. Ne faut-il pas pour atteindre l'univers de l'enfant (je ne dis pas le monde enfantin), franchir l'espace, trouver le point de vue, l'angle, I'ouverture, ne faut-il pas remonter le temps, prendre du recul (j'aurais pu dire de l'avance), identifier ses conditionnements, se (re)faire une sorte de candeur consciente et/ou de conscience candide. La problématique de l'écriture du conte pour enfants ne réside-t-elle pas dans la réalisation d'une fusion équilibrée du plausible et du merveilleux au fil d'une narration exploitant toutes 